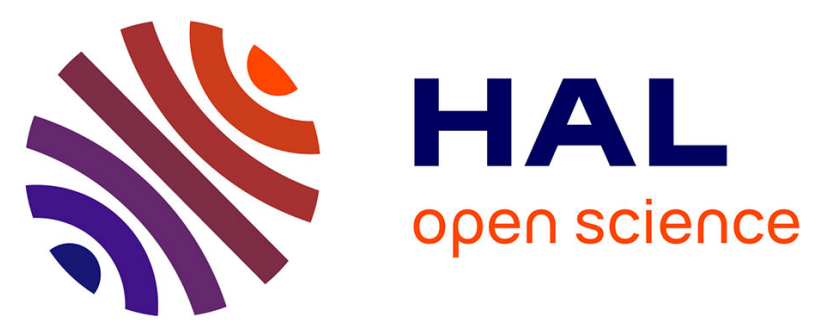

\title{
Confronting molecular rotors and self-quenched dimers as fluorogenic BODIPY systems to probe biotin receptors in cancer cells
}

Kyong T Fam, Lazare Saladin, Andrey S Klymchenko, Mayeul Collot

\section{- To cite this version:}

Kyong T Fam, Lazare Saladin, Andrey S Klymchenko, Mayeul Collot. Confronting molecular rotors and self-quenched dimers as fluorogenic BODIPY systems to probe biotin receptors in cancer cells. Chemical Communications, 2021, 57, pp.4807 - 4810. 10.1039/d1cc00108f . hal-03419806

\author{
HAL Id: hal-03419806 \\ https://hal.science/hal-03419806
}

Submitted on 10 Nov 2021

HAL is a multi-disciplinary open access archive for the deposit and dissemination of scientific research documents, whether they are published or not. The documents may come from teaching and research institutions in France or abroad, or from public or private research centers.
L'archive ouverte pluridisciplinaire $\mathbf{H A L}$, est destinée au dépôt et à la diffusion de documents scientifiques de niveau recherche, publiés ou non, émanant des établissements d'enseignement et de recherche français ou étrangers, des laboratoires publics ou privés. 


\section{Journal Name}

\section{COMMUNICATION}

\section{Confronting Molecular Rotor and Self-Quenched Dimer as Fluorogenic BODIPY Systems to Probe Biotin Receptors in Cancer Cells}

Received 00th January 20xx, Accepted 00th January 20xx

DOI: $10.1039 / x 0 x \times 00000 x$

\section{www.rsc.org/}

Probing receptors at the cell surface to monitor their expression level can be performed with fluorogenic dyes. Biotin receptors (BRs) are particularly interesting as they are overexpressed in cancer cells. Herein, to image BRs we adapted and systematically compared two fluorogenic systems based on BODIPYs: a molecular rotor and a self-quenched dimer that respectively light up in response to high viscosity and low polarity of the membrane. The fluorogenic dimer proved to be more efficient than the rotor and allowed to image BRs in cancer cells that can effectively be discriminated from non-cancer ones.

The entry of biomolecules into live cells is controlled at the level of the plasma membrane, where receptors are heterogeneously expressed depending on the state of the cell. Imaging those receptors is important to monitor the variation of their expression level and can be performed by fluorescent labeling of the corresponding ligands. In order to avoid high background noise in imaging provoked by unbound ligands, fluorogenic probes (fluorogens) that light up only upon target binding were developed. ${ }^{1}$ These probes rely on the change of their environment upon the ligand/receptor interaction mainly due to the proximity with the plasma membrane that constitutes a non-polar and viscous medium. ${ }^{2,3,4,5,6}$ A number of environment-sensitive probes, exploiting different photophysical principles, were exploded to detect local membrane properties, ${ }^{7}, 8,9,10$ viscosity-sensitive molecular rotors $^{4,11,12,13}$ and membrane-tension sensitive flippers. ${ }^{14,15,16}$ In the context of cell surface receptors, different approaches were considered. Single fluorogens were successfully used like water-quenched squaraine, ${ }^{17}$ solvatochromic Nile Red, ${ }^{18,}$ 19, 20 dioxaborine with viscosity and polarity sensitivity, ${ }^{21}$ and BODIPY molecular rotor. ${ }^{22}$ Systems based on aggregationcaused quenching $(\mathrm{ACQ})^{23}$ and aggregation-induced

\footnotetext{
a. Laboratoire de Bioimagerie et Pathologies, UMR 7021, CNRS/Université de Strasbourg, 74 route du Rhin, 67401 IIlkirch-Graffenstaden, France. E-mail: andrey.klymchenko@unistra.fr, mayeul.collot@unistra.fr

+ Electronic Supplementary Information (ESI) available: protocols, NMR and mass spectra, full photophysical characterisations, cytotoxicity assays. See DOI: $10.1039 / x 0 x x 00000 x$
}

emission ${ }^{24}$ were also proposed as nanoprobes. In particular, intermolecular aggregation of dyes have been exploited obtain light up probes for membrane. ${ }^{25,26}$ Our group recently reported dimeric fluorogens that undergo dimerization-caused quenching (DCQ) based on squaraine ${ }^{27,28}$ for membrane receptor imaging in cells and those based on near-infrared cyanines for in vivo receptor imaging. ${ }^{29}$ This DCQ systems provide high signal/background ratio images due to high fluorescence quenching in the media, and enhanced brightness once bound to the receptor enabled by turning on two fluorophores instead of one. We recently used this approach to probe biotin receptors, which are overexpressed in cancer cells. ${ }^{28}$

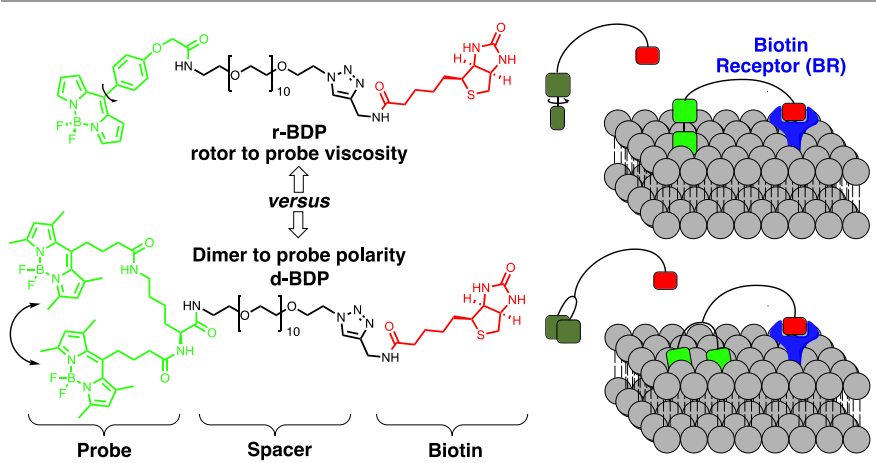

Figure 1. Two fluorogenic probes for biotin receptors based on BODIPY molecular rotor (r-BDP) and dimerized BODIPY (d-BDP).

In this work, we performed a comparative analysis by confronting two fluorogenic approaches to develop sensitive membrane receptor targeting probe: the polarity sensitive DCQ fluorogenic system and the viscosity sensitive molecular rotor approach. Consequently, the cell surface biotin receptor (BR) was chosen as a model to confront the two fluorogenic systems based on the same BODIPY fluorophore. Indeed, among the fluorescent markers, BODIPYs possess appealing properties for bioimaging including high brightness, narrow excitation and emission bands along with robust photostability. $^{30,31,32}$ Moreover, molecular rotors based on BODIPY are widely used in bioimaging, ${ }^{33}$ and proved their 
efficiency in probing the viscosity of membranes, ${ }^{34,} 35$ mitochondria, $^{36}$ lysosomes $^{37}$ and apoptosis. ${ }^{22}$ We thus designed two fluorogenic probes bearing both a biotin ligand at their one end and which display at the opposite end: 1) a single BODIPY molecular rotor (rBDP) that responds to the increase of the membrane viscosity or 2) a dimerized BODIPY linked through a lysine (d-BDP) that turns on upon decrease of the polarity once in the membrane (Figure 1).
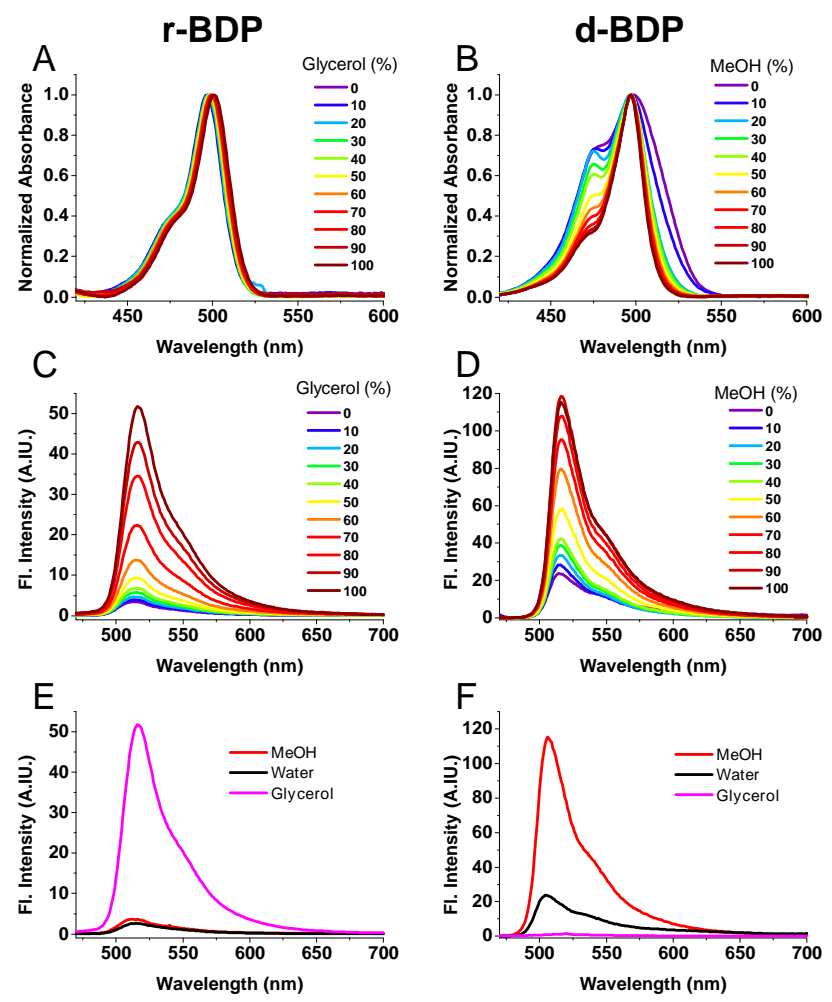

Figure 2. (A) Normalized absorption spectra ( $A$ and $B$ ) and emission spectra ( $C$ and $D)$ of $\mathbf{r - B D P}$ in various water/MeOH mixtures and $\mathbf{d}$-BDP in various glycerol/MeOH mixture. ( $E$ and $F$ ) Emission spectra of $\mathbf{r}$-BDP and d-BDP respectively, in water, methanol and glycerol. Concentration of the probes was $1 \mu \mathrm{M}$. Excitation wavelength was $460 \mathrm{~nm}$.

To compensate the difference of hydrophobicity owning to the two fluorogenic systems, the biotin ligand was separated by a long $\mathrm{PEG}_{12}$ chain that also intended to enhance the water solubility and to limit the non-specific interactions (Figure 1). ${ }^{38}$ Once obtained and characterized (NMR, mass spectroscopy, see $\mathrm{SI}$ ), we ensured that $\mathbf{r}$-BDP and $\mathbf{d}$-BDP were respectively responsive to the viscosity and the polarity. As expected $\mathbf{r}$-BDP displayed a fluorogenic response (14.9-fold) upon increase of viscosity using water/glycerol mixtures whereas d-BDP showed a fluorescence enhancement of 4.9-fold from water to methanol. Whereas the absorption spectra of $\mathbf{r}$-BDP did not change upon increase of viscosity denoting a full solubility in the media, those of d-BDP displayed an increasing blue-shifted band at $\sim 470 \mathrm{~nm}$ upon increasing content of water. This band was assigned to intramolecular $\mathrm{H}$-aggregates of BODIDYs. To confirm that d-BDP undergoes intramolecular self-quenching, and not intermolecular aggregation, the absorption spectra of the dimer at different concentration was recorded (Figure S1). The presence of the $\mathrm{H}$-aggregate band in the concentration range from $50 \mathrm{nM}$ to $1 \mu \mathrm{M}$ suggested that the dimer underwent dimerization-caused quenching in the studied concentration range without significant contribution of intermolecular aggregation. We then cross-checked that r-BDP was not sensitive to the polarity and that d-BDP was not sensitive to the viscosity (Figure $2 \mathrm{C}-\mathrm{F}$ ). As expected, the fluorescence of $\mathbf{r}$-BDP did not change from water to methanol (Figure 2F), which are both non-viscous solvents. In glycerol, $\mathbf{d}$ BDP did not turn on and showed a lower intensity than in water (Figure $2 \mathrm{C}$ ), probably due to a lower solubility in glycerol than in water. Although $\mathbf{r - B D P}$ triggered a superior fluorescence enhancement compared to d-BDP (14.9 and 4.9 respectively), it is important to note that the brightness of the dimer is significantly higher than the one of the rotor due to a higher quantum yield in the $\mathrm{ON}$ state $(0.60$ and 0.27 respectively) and also because the dimer is composed of two fluorophores. Overall, at the ON state the dimer is more than 4-fold brighter compared to the rotor (see table 1). Conversely, r-BDP displayed a much higher photostability compared to d-BDP in their respective "turn-on" conditions (Figure S2). Experiments in various model biological environments (proteins, lipid membranes, etc) showed that both probes did not undergo significant off-target fluorogenic response. As expected, the dimer was only sensitive to lipids (DOPC vesicles and SDS surfactant) that provoke a change of local polarity, whereas the rotor displayed a fluorescence enhancement only in highly viscous glycerol (Figure S3).

Table 1. Photophysical properties of the BODIPY probes $(1 \mu \mathrm{M})$.

\begin{tabular}{|c|c|c|c|c|c|c|c|}
\hline Probe & Solvent & $\begin{array}{c}\text { Abs } \\
(\mathrm{nm})\end{array}$ & $\left(\mathrm{M}^{-1} \cdot \mathrm{cm}^{-1}\right)$ & $\begin{array}{c}\mathrm{Em} \\
(\mathrm{nm})\end{array}$ & a & $\begin{array}{c}\text { Brightness }^{b} \\
\left(\mathrm{M}^{-1} \cdot \mathrm{cm}^{-1}\right)\end{array}$ & $\begin{array}{l}\text { FI. En. } \\
\text { (-fold) }\end{array}$ \\
\hline \multirow{2}{*}{ r-BDP } & Water & 497 & 50,000 & 515 & 0.03 & 1,500 & \multirow{2}{*}{14.9} \\
\hline & Glycerol & 501 & 50,000 & 516 & 0.27 & 13,500 & \\
\hline \multirow{2}{*}{ d-BDP } & Water & 499 & 60,000 & 504 & 0.17 & 10,200 & \multirow{2}{*}{4.9} \\
\hline & $\mathrm{MeOH}$ & 497 & 160,000 & 506 & 0.60 & 96,000 & \\
\hline
\end{tabular}

${ }^{a}$ The quantum yields were measured by comparison with fluorescein, $\phi=0.95$ in water $(\mathrm{NaOH}, 0.1 \mathrm{M}) .^{39}$

${ }^{\mathrm{b}}$ The brightness is defined as: $\varepsilon \times \phi$.

${ }^{c}$ Fluorescence enhancement at the maximum emission wavelength. $F / F_{\text {water }}$.

After checking that the two probes did not affect the viability of cells as high as $5 \mu \mathrm{M}$ (Figure S4), their ability to probe $\mathrm{BR}$ were evaluated in confocal imaging using $B R$ positive $K B$ cells. ${ }^{40}$ The probes were added to the cells at $200 \mathrm{nM}$ and imaged 2 min later without any washing step (Figure 3). In addition to a nuclear staining using Hoechst, MemBright-Cy5 was used to localize the plasma membrane. ${ }^{41}$ Surprisingly, at the same imaging conditions and using the same settings $r$ BDP was undetectable, whereas d-BDP rapidly displayed a bright signal at the plasma membrane leading to images with high signal/background ratio (Figure 3 ). When the laser power was increased, images obtained with r-BDP displayed a high background signal with low cytoplasmic and membrane signal (Figure S5). However, by increasing both incubation time (30 min) and probe concentration $(1 \mu \mathrm{M})$ r-BDP could also report BRs (Figure S6). This difference could be assigned to a slow membrane insertion of the rotor moiety compared to the relatively more hydrophobic dimer. 

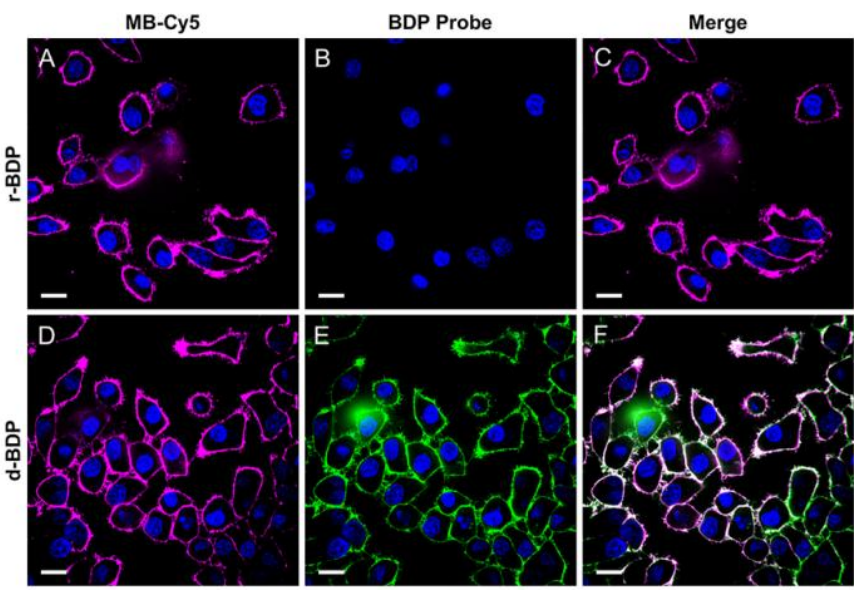

Figure 3. Confocal spinning disk imaging of $K B$ cells in the presence of BODIPY probes (200 nM), r-BDP (A-C) and d-BDP (D-F). The nucleus was stained with Hoechst (5 $\mu \mathrm{g} / \mathrm{mL}$, blue color) and the plasma membrane with MemBright-Cy5 (20 nM, Magenta color). Scale bar is $20 \mu \mathrm{m}$.

To confirm the specificity of $\mathbf{d - B D P}$, several controls were performed. First, two cancer cell lines (KB, HeLa) that overexpress $\mathrm{BRs}$ were compared to two non-cancer cell lines (HEK293T, NIH/3T3) ${ }^{40}$ in the presence of d-BDP (Figure 4A-B and figure S7). The results showed that only cancer cells were brightly stained in imaging with notable signal shifts in flow cytometry analysis compared to non-cancer cells (Figure 4C), proving the minimal non-specific binding to the plasma membrane. As a second control, KB cells were incubated with free biotin to saturate the BR prior to addition of d-BDP. As expected pre-incubation with biotin led to a dramatic decrease of the d-BDP signal (Figure 4D), denoting the selectivity of the probe for the BRs. BR such as sodium dependent multivitamin transporter (SMVT) translocates other vitamins such as lipoic acid. $^{28,42}$ Pretreatment of KB cells with lipoic acid (Figure 4E) or a sodium depletion in the medium (sodium was replaced by choline, figure 4F) significantly decreased the d-BDP signal denoting the important implication of SMVT in the uptake of biotin in KB cells. As a final experiment, we assessed the ability of $\mathbf{d - B D P}$ to detect cancer cells in the presence of noncancer ones by fluorescence imaging. To this endeavor, d-BDP was added to co-cultured non-cancer HEK293T and cancer KB cells along with the plasma membrane probe MemBright-Cy5 (Figure 4G-I). After $10 \mathrm{~min}$ of incubation and no washing step, the cancer KB cells (easily identifiable by their shape in transmitted-light microscopy) displayed a bright green fluorescence whereas non-cancer HEK293T cells were not stained. This experiment proved that d-BDP is able to discriminate cancer cells among non-cancer ones based on the overexpression biotin receptors.

In conclusion, we herein constructed two PEGylated and biotinylated molecules ended by two different fluorogenic systems based on BODIPY to probe BR in cells. Whereas r-BDP is based on a BODIPY rotor, which is sensitive to the viscosity, d-BDP is based on dimerized self-quenched BODIPY that lights up when the polarity of the medium is decreased. Although $\mathbf{r}$ BDP showed higher fluorescence enhancement in spectroscopy, cellular imaging revealed its poor ability to probe BR, unless optimized conditions were applied. Conversely, d-BDP immediately and efficiently stained BRs in cancer cells at low concentration due to its high brightness and selectivity making it usable to detect cancer cells among noncancer ones. This difference might be attributed to the weak variation of the local viscosity at the proximity of the biotin receptors or the low affinity of the rotor for the plasma membrane. This work intends to show that special attention should be drawn to the design of the chosen fluorogenic systems while developing a receptor-targeting probe. Although molecular rotors proved their efficiency as fluorescent probes for studying variations of viscosity in biomembranes, $4,11,12,13$ this study showed that it might not be adapted as fluorogenic probe for imaging membrane receptors. Possible reason could be insufficient insertion or interaction of the r-BDP fluorophore into the lipid membrane due to its lower lipophilicity compared to the dimer reporter as well as significantly lower membrane viscosity compared to that of glycerol (140 cP vs $1410 \mathrm{cP}$ ). ${ }^{11}$ This work also confirms the ability of systems based on dimerization-caused quenching to probe receptors localized at the plasma membrane. In order to light up, the dimer requires relatively small decrease in the polarity (from water to methanol), which explains its capacity to detect local polarity changes on receptor binding. This fluorogenic response to receptor binding and high brightness of two dyes makes the dimer-based probes particularly attractive for receptor imaging applications.
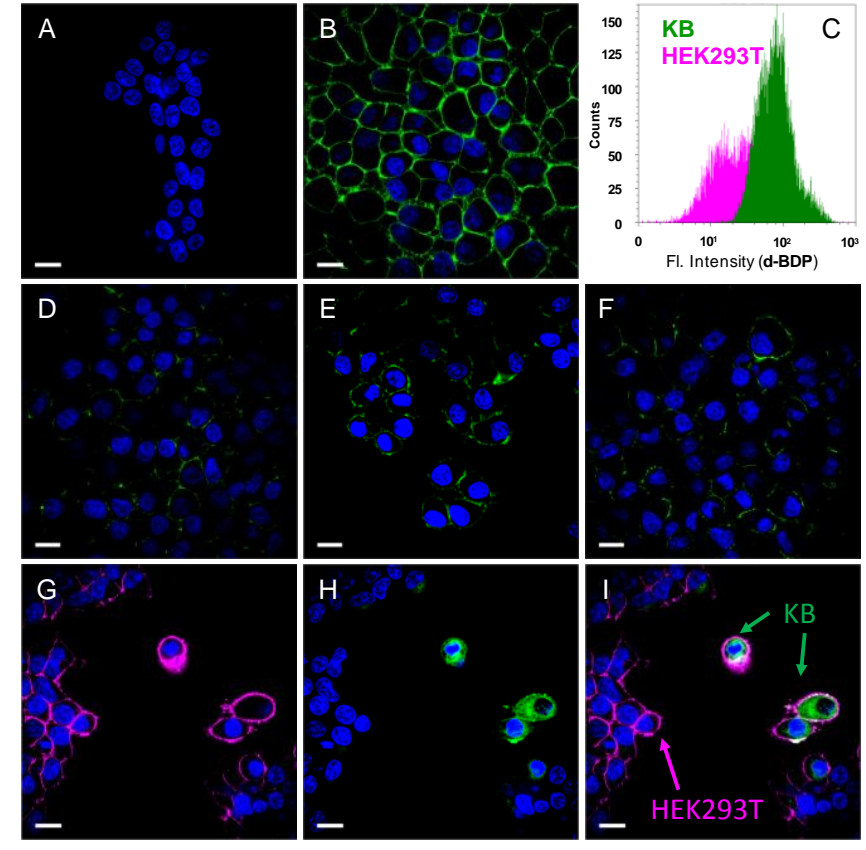

Figure 4. Confocal spinning disk imaging using d-BDP (200 nM) with HEK293T cells (A) and $K B$ cells (B). (C) is the histogram obtained by flow cytometry (exc. $488 \mathrm{~nm}$ ). Images of KB cells after adding d-BDP and pre-incubated with $0.1 \mathrm{mM}$ biotin (D), $0.1 \mathrm{mM}$ lipoic acid (E) and sodium-depleted medium (F). (G-I) Mixture of HEK293T and KB cells incubated with d-BDP for $10 \mathrm{~min}$. $(G)$ is the MemBright-Cy5 channel, $(H)$ is the BDP channel and (I) is the merge of channels. d-BDP was excited at $488 \mathrm{~nm}$ (green color), Hoechst at $405 \mathrm{~nm}$ (blue color), and MemBright-Cy5 at $638 \mathrm{~nm}$ (magenta color). Scale bar is $20 \mu \mathrm{m}$. 


\section{Conflict of interest}

There are no conflicts to declare.

\section{Notes and references}

1 A. S. Klymchenko, Acc. Chem. Res., 2017, 50, 366-375.

2 D. Kurad, G. Jeschke and D. Marsh, Biophys. J., 2003, 85, 10251033.

3 M. E. Nipper, S. Majd, M. Mayer, J. C.-M. Lee, E. A. Theodorakis and M. A. Haidekker, Biochim. Biophys. Acta BBA - Biomembr., 2008, 1778, 1148-1153.

4 M. K. Kuimova, Phys. Chem. Chem. Phys., 2012, 14, 1267112686.

5 A. S. Klymchenko and R. Kreder, Chem. Biol., 2014, 21, 97-113.

6 J. Steinkühler, E. Sezgin, I. Urbančič, C. Eggeling and R. Dimova, Commun. Biol., 2019, 2, 1-8.

7 T. Parasassi, E. K. Krasnowska, L. Bagatolli and E. Gratton, J. Fluoresc., 1998, 8, 365-373.

8 A. P. Demchenko, Y. Mély, G. Duportail and A. S. Klymchenko, Biophys. J., 2009, 96, 3461-3470.

9 O. A. Kucherak, S. Oncul, Z. Darwich, D. A. Yushchenko, Y. Arntz, P. Didier, Y. Mély and A. S. Klymchenko, J. Am. Chem. Soc., 2010, 132, 4907-4916.

10 A. H. Ashoka, P. Ashokkumar, Y. P. Kovtun and A. S. Klymchenko, J. Phys. Chem. Lett., 2019, 10, 2414-2421.

11 M. K. Kuimova, G. Yahioglu, J. A. Levitt and K. Suhling, J. Am. Chem. Soc., 2008, 130, 6672-6673.

12 M. A. Haidekker and E. A. Theodorakis, Org. Biomol. Chem. 2007, 5, 1669-1678.

13 J. E. Chambers, M. Kubánková, R. G. Huber, I. López-Duarte, E. Avezov, P. J. Bond, S. J. Marciniak and M. K. Kuimova, ACS Nano, 2018, 12, 4398-4407.

14 M. Dal Molin, Q. Verolet, A. Colom, R. Letrun, E. Derivery, M. Gonzalez-Gaitan, E. Vauthey, A. Roux, N. Sakai and S. Matile, J. Am. Chem. Soc., 2015, 137, 568-571.

15 A. Colom, E. Derivery, S. Soleimanpour, C. Tomba, M. D. Molin, N. Sakai, M. González-Gaitán, S. Matile and A. Roux, Nat. Chem., 2018, 10, 1118-1125.

16 A. Goujon, A. Colom, K. Straková, V. Mercier, D. Mahecic, S. Manley, N. Sakai, A. Roux and S. Matile, J. Am. Chem. Soc., 2019, 141, 3380-3384.

17 I. A. Karpenko, A. S. Klymchenko, S. Gioria, R. Kreder, I. Shulov, P. Villa, Y. Mély, M. Hibert and D. Bonnet, Chem. Commun., 2015, 51, 2960-2963.

18 E. Prifti, L. Reymond, M. Umebayashi, R. Hovius, H. Riezman and K. Johnsson, ACS Chem. Biol., 2014, 9, 606-612.

19 X. Kong, B. Dong, N. Zhang, C. Wang, X. Song and W. Lin, Talanta, 2017, 174, 357-364.

20 I. A. Karpenko, R. Kreder, C. Valencia, P. Villa, C. Mendre, B. Mouillac, Y. Mély, M. Hibert, D. Bonnet and A. S. Klymchenko, ChemBioChem, 2014, 15, 359-363.

21 I. A. Karpenko, Y. Niko, V. P. Yakubovskyi, A. O. Gerasov, D. Bonnet, Y. P. Kovtun and A. S. Klymchenko, J. Mater. Chem. C, 2016, 4, 3002-3009.

22 P. Ashokkumar, A. H. Ashoka, M. Collot, A. Das and A. S. Klymchenko, Chem. Commun., 2019, 55, 6902-6905.

23 A. Okamoto, Chem. Soc. Rev., 2011, 40, 5815-5828.

24 J. Liang, B. Z. Tang and B. Liu, Chem. Soc. Rev., 2015, 44, 27982811.
25 K. Mizusawa, Y. Ishida, Y. Takaoka, M. Miyagawa, S. Tsukiji and I. Hamachi, J. Am. Chem. Soc., 2010, 132, 7291-7293.

26 K. Mizusawa, Y. Takaoka and I. Hamachi, J. Am. Chem. Soc., 2012, 134, 13386-13395.

27 I. A. Karpenko, M. Collot, L. Richert, C. Valencia, P. Villa, Y. Mély, M. Hibert, D. Bonnet and A. S. Klymchenko, J. Am. Chem. Soc., 2014, 137, 405-412.

28 K. T. Fam, M. Collot and A. S. Klymchenko, Chem. Sci., 2020, 11, 8240-8248.

29 L. Esteoulle, F. Daubeuf, M. Collot, S. Riché, T. Durroux, D. Brasse, P. Marchand, I. A. Karpenko, A. S. Klymchenko and D. Bonnet, Chem. Sci., 2020, 11, 6824-6829.

30 T. Kowada, H. Maeda and K. Kikuchi, Chem. Soc. Rev., 2015, 44, 4953-4972.

31 G. Ulrich, R. Ziessel and A. Harriman, Angew. Chem. Int. Ed., 2008, 47, 1184-1201.

32 M. Collot, E. Boutant, M. Lehmann and A. S. Klymchenko, Bioconjug. Chem., 2019, 30, 192-199.

33 W. Miao, C. Yu, E. Hao and L. Jiao, Front. Chem., 2019, 7, 825.

34 S. Raut, J. Kimball, R. Fudala, H. Doan, B. Maliwal, N. Sabnis, A. Lacko, I. Gryczynski, S. V. Dzyuba and Z. Gryczynski, Phys. Chem. Chem. Phys., 2014, 16, 27037-27042.

35 I. López-Duarte, T. T. Vu, M. A. Izquierdo, J. A. Bull and M. K. Kuimova, Chem. Commun., 2014, 50, 5282-5284.

36 X. Song, N. Li, C. Wang and Y. Xiao, J. Mater. Chem. B, 2017, 5, 360-368.

37 L. Wang, Y. Xiao, W. Tian and L. Deng, J. Am. Chem. Soc., 2013, 135, 2903-2906.

38 F. Ponsot, W. Shen, P. Ashokkumar, E. Audinat, A. S. Klymchenko and M. Collot, ACS Sens., 2017, 2, 1706-1712.

39 J. R. Lakowicz, Ed., Principles of Fluorescence Spectroscopy, Springer US, Boston, MA, 2006.

40 W. X. Ren, J. Han, S. Uhm, Y. J. Jang, C. Kang, J.-H. Kim and J. S. Kim, Chem. Commun. Camb. Engl., 2015, 51, 10403-10418.

41 M. Collot, P. Ashokkumar, H. Anton, E. Boutant, O. Faklaris, T. Galli, Y. Mély, L. Danglot and A. S. Klymchenko, Cell Chem. Biol., 2019, 26, 600-614.e7.

42 A. D. Vadlapudi, R. K. Vadlapatla and A. K. Mitra, Curr. Drug Targets, 2012, 13, 994-1003. 